\title{
Morbid Obesity: A World View
}

\author{
Marco G. Patti
}

Published online: 22 July 2009

(c) Société Internationale de Chirurgie 2009

The International Society of Digestive Surgery (ISDS), formerly Collegium Internationale Chirurgiae Digestivae, is a surgical organization with members located all over the world. The focus of the ISDS is the study of disorders of the gastrointestinal tract, from physiology to pathophysiology, from diagnosis to treatment. The world meeting of this organization occurs every two years, and in 2009 the 21st meeting of the ISDS will be held September 6-10 in Adelaide, Australia, together with the meeting of the International Surgical Society (ISS).

Also starting this year, the ISDS has chosen the World Journal of Surgery as its official journal, because the international character of this journal matches the goals and membership of the ISDS. We think that it will be a very productive association.

In this issue, the ISDS is pleased to sponsor its first symposium in the World Journal of Surgery. We have chosen the most pressing condition requiring digestive surgery in the world today, obesity. I am honored to co-edit this symposium with Bruce Wolfe, an internationally recognized authority and the surgical leader of the U.S. National Institutes of Health (NIH) funded collaborative, the Longitudinal Assessment of Bariatric Surgery. For this symposium we have assembled a group of world experts who have focused their career toward the treatment of this condition.

M. G. Patti ( $\varangle)$

University of Chicago Pritzker School of Medicine,

Chicago, IL, USA

e-mail: mpatti@surgery.bsd.uchicago.edu 